on the site (there are 1,200 altogether) are chemists by training. For the institute, originally founded as a natural product laboratory in 1959 (Lysenko's time), is now the spearhead of the academy's effort in genetic engineering. It is the creation of 52-year-old Academician Yuri Ovchinnikov, vice-president of the academy and a long-standing enthusiast for biotechnology. (Ovchinnikov, who has been a frequent visitor to the West in recent years, is now gravely ill.)

Just why the building should be so lavishly equipped is far from clear. Is it meant as a model of excellence in laboratory furnishing at which others may strive? A recognition of the importance attached to genetic engineering in the Soviet Union? A mixture of the two? Or something else?

Whatever the case, students, of whom there are $50-60$ a year, are dealt with well. They have an excellent set of seminar rooms and laboratories (plus Asian corridor-carpets). The institute organizes subdepartments within biology at the Moscow Physical-Technical Institute and at the Moscow State University.

What of the research? Acting director V.F. Bystrov, himself a structural organic

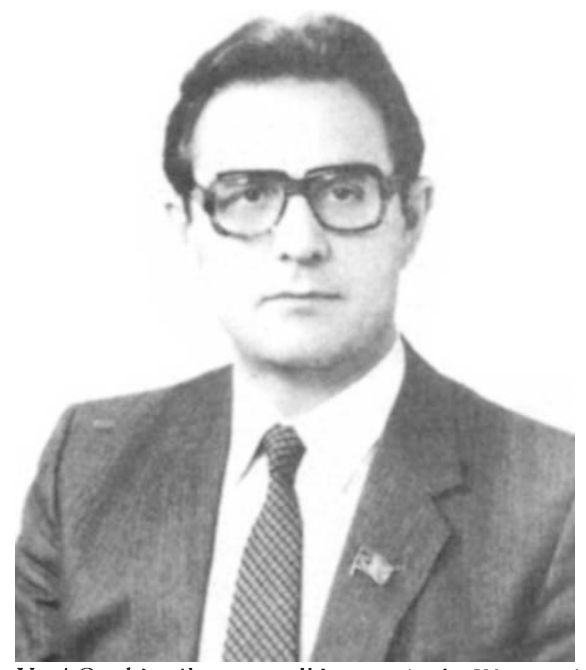

Yuri Ovchinnikov - well known in the West and now author of a major textbook.

chemist, says that a wide-ranging programme of research has taken the institute more or less to where people are in the West. The production of monoclonal antibodies is routine, there are diagnostic tests for infection by the viruses of AIDS (acquired immune deficiency syndrome), hepatitis B and, interestingly, potato mosaic virus.

The development of a technique for producing molecules of tumour necrosis factor (TNF) is complete, and animal toxicity tests preliminary to clinical trials with people are about to begin; Bystrov seemed slightly startled at the suggestion that TNF may be like yet another lymphokine - a naturally occurring biological material whose effects are somewhat ambivalent when tested in vitro.

Ovchinnikov's many detractors (envy of the extravagance is rife) overlook his achievements. He has been an enthusiast of genetic manipulation since 1972. At an early stage, he recognized that the prosecution of research in molecular biology would require a supply of materials such as restriction enzymes and radioactive chemicals; there is now a plant at Riga, in the Baltic Republic of Latvia, which produces restriction enzymes and which is also a subsidiary centre of research, especially in toxicity testing and the organization of clinical trials.

Ovchinnikov has also arranged for the production of radioactive chemicals at Tashkent in Central Asia. It cannot be his fault, but that of a production ministry, that the supply is often interrupted, especially in the summer, for periods longer than the 12-day half-life of phosphorus-32. Arrangements for the production of oligonucleotides of specified sequence have not panned out so well.

The Shemiakin Institute is not just a laboratory, however, but the centre of the Soviet Union's web of interest in biotechnology: Ovchinnikov is also chairman of the 65-strong interministerial committee coordinating the activities of more than 200 scientific institutions with an interest in biotechnology. The institute also runs the academy's internal councils on biological membranes and bioorganic chemistry, publishing the two associated Russian-language journals. Ovchinnikov's limitless energy has nevertheless enabled him also to write a major textbook (Bioorganic Chemistry, Prosveshcheniye, Moscow, 1987) as well as to participate in many scientific papers.

\title{
Lebedev Institute
}

\section{High-temple of Soviet physics}

THE remarkable Lebedev Institute is a geographically puzzling place. Opposite the main entrance is a building that might be mistaken for a Grecian temple were it not wisely enclosed, a few metres behind the Doric columns, against the hard Moscow winter. That turns out to be the administration block.

The director, Academician N.G. Basov, and his colleagues, are to be found some hundreds of metres behind the imposing entrance, in a laboratory block built, as V.L. Ginzburg quickly explains, on a plot of ground on which people used to grow potatoes in the years immediately after the Second World War.

Closer inspection shows that the institute is not nearly as old as it looks. The first building was in reality put up only in 1951. And behind the imposing facades, many of the laboratory buildings are faced with simple brick. The campus is a kind of simulation of MIT's mix of mock-factories and mock-palaces.

The Lebedev Institute, with all its ramifications, is probably one of the most important concentrations of physicists in the world. Los Alamos would probably give it a close run for its money (and would not have as great a proportion of theoreticians on its payroll of 4,000 , at least a quarter of those professionally qualified).

Basov was awarded a Nobel Prize for his contributions to the development of lasers, and he remains active in quantum optics. But he and V.L. Ginzburg, the chief of the theoretical physics laboratory, are anxious to make it plain that the reputation of their institute stems from the great men who have passed through it: Mandelstam, Lansberg, 'Tamm, Landau, Fock, Fraenkel

Ginzburg, almost certainly the most- active septuagenarian physicist now working every day, and musing on the delectable prospect that he might give up his administrative responsibilities next year, suggests that finding a successor may be difficult with the intelligence that "Sakharov has not been back very long".

Basov is more bullish about the Lebedev. He notes that since the foundation of the institute with the arrival of the St Peterburg academy in Moscow in 1934, with its first director Sergei Vavilov (the brother of the geneticist), no fewer than a dozen academy institutes have been created by the centrifugal tendencies of its various members. Dubna, the now international nuclear research centre, is one of them. "The devotion of our people to science", says Basov, is "extraordinary, enormous".

Ginzburg's view is longer and more down-to-earth. "Just after the war, physics was at the top of its peak - people respected physics more than they respected posts [a reference to the late Lev Landau]". But then salaries went up, there were more people, then other people's salaries increased, now there are probably too many people

This is not the jaundiced comment it may seem. Ginzburg is as active as ever, but the Lebedev is sadly hampered by the serious lack of up-to-date equipment. It would like to be more like Bell-AT\&T Laboratories than it is (and is ready to show off a compact electron tube $10 \mathrm{~cm}$ across with a spot-size of $10 \mu \mathrm{m}$ across that may be able to drive a cinema screen through a suitably laser-etched mask). But for lack of equipment, the theoretical division grows at the expense of the others. Ginzburg and Basov seem to have teased each other about that often. 